\title{
Errata
}

\section{Erratum: Hagler et al., "Heterogeneous Origins of Human Sleep Spindles in Different Cortical Layers"}

In the article "Heterogeneous Origins of Human Sleep Spindles in Different Cortical Layers" by Donald J. Hagler, István Ulbert, Lucia Wittner, Loránd Erőss, Joseph R. Madsen, Orrin Devinsky, Werner Doyle, Dániel Fabó, Sydney S. Cash, and Eric Halgren, which appeared on pages 3013-3025 of the March 21, 2018 issue, formatting errors were accidentally introduced into Figure $8 B$ during the printing process. The figure has been corrected on-line, and is displayed below. This correction does not affect the conclusions of the paper.

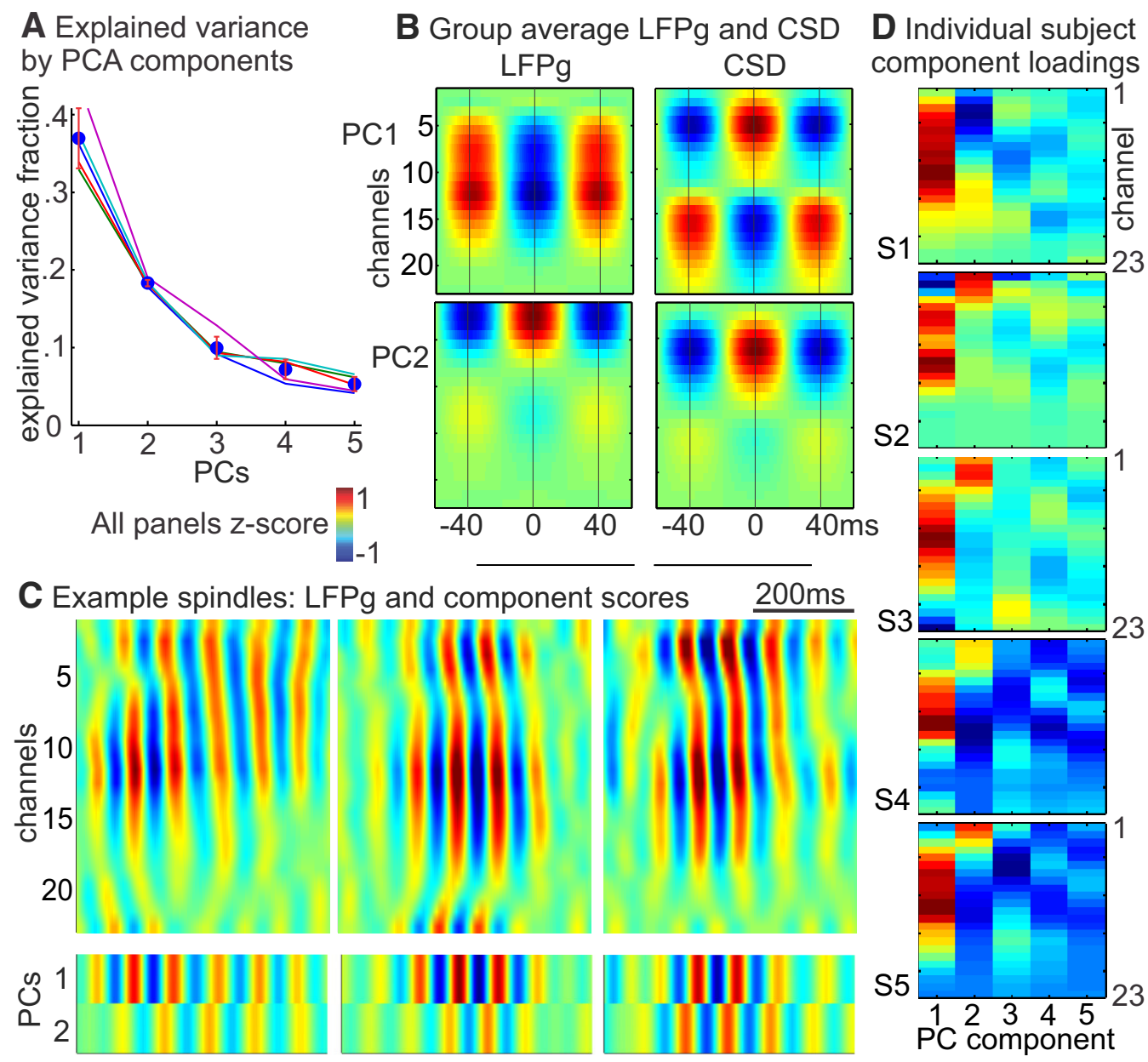

Figure 8.

DOI:10.1523/JNEUROSCI.0788-18.2018

\section{Erratum: Hannah et al., "Selective Suppression of Local Interneuron Circuits in Human Motor Cortex Contributes to Movement Preparation"}

In the article "Selective Suppression of Local Interneuron Circuits in Human Motor Cortex Contributes to Movement Preparation” by Ricci Hannah, Sean E. Cavanagh, Sara Tremblay, Sara Simeoni, and John C. Rothwell, which appeared on pages 1264-1276 of the January 31, 2018 issue, a citation was inadvertently omitted from the reference list by the printer. The entry, cited in the text as Hannah and Rothwell, 2017, has been corrected on-line, and is displayed below. This correction does not affect the conclusions of the paper. 


\section{Reference}

Hannah R, Rothwell JC (2017) Pulse duration as well as current direction determines the specificity of transcranial magnetic stimulation of motor cortex during contraction. Brain Stimul 10:106-115. 10.1016/j.brs.2016.09.008 28029595

DOI:10.1523/JNEUROSCI.0792-18.2018 